\title{
Bleeding and cerebral injury following aortic arch repair: Two chinks in the armor
}

\author{
John S. Ikonomidis, MD, PhD
}

\author{
From the Division of Cardiothoracic Surgery, Medical University of South Carolina, Charleston, SC. \\ Disclosures: Author has nothing to disclose with regard to commercial support. \\ Received for publication Aug 28, 2015; accepted for publication Aug 29, 2015; available ahead of print \\ Oct 1,2015 . \\ Address for reprints: John S. Ikonomidis, MD, PhD, Division of Cardiothoracic Surgery, Medical University of \\ South Carolina, 114 Doughty St, Suite BM 282, Charleston, SC 29425 (E-mail: ikonomij@musc.edu). \\ J Thorac Cardiovasc Surg 2016;151:296-7 \\ $0022-5223 / \$ 36.00$ \\ Copyright (c) 2016 by The American Association for Thoracic Surgery \\ http://dx.doi.org/10.1016/j.jtcvs.2015.08.113
}

Aortic arch repair remains a complex, technically challenging procedure, even in the most experienced of hands. It has been very interesting to watch the progression of techniques and strategies employed to overcome the everpresent risks of stroke and hemorrhage associated with these operations. The question is, Have we made progress?

The modern era of aortic arch replacement was ushered in with the landmark article by Griepp and colleagues ${ }^{1}$ who described 4 patients who underwent profound hypothermic circulatory arrest for aortic arch replacement. Since that time, many articles have been published documenting different surgical strategies and approaches to cerebral protection during aortic arch surgery. Cerebral protection strategies have progressed from profound hypothermic circulatory arrest with no perfusion adjuncts to introduction of retrograde cerebral perfusion via the snared superior vena cava, then antegrade cerebral perfusion via the innominate artery, left common carotid artery, or the axillary artery. While this was occurring, several studies were performed to identify safe temperatures for profound hypothermic circulatory arrest, followed by emerging evidence that increasing (ie, less cold) the lowest systemic temperature for circulatory arrest results in at least equivalent outcomes and in fact may be better than perfusion at lower temperatures. Where do we stand with all of this currently?

Whereas historically it was not uncommon to cool patients to the low teens Celsius in an effort to achieve cerebral protection during aortic arch replacement, trials from numerous centers from around the world have demonstrated the clinical efficacy of adult aortic arch repair with antegrade cerebral perfusion (ACP) and mild to moderate hypothermia in the range of $22^{\circ} \mathrm{C}$ to $30^{\circ} \mathrm{C}$. A contemporary review of questionnaires distributed at international conferences in Bejing and Milan in 2010 showed that the typical strategy for adult aortic arch repair was moderate hypothermia with bilateral ACP, particularly prevalent in Europe. ${ }^{2}$ Tian and colleagues ${ }^{3}$ conducted a meta-analysis of 9 studies and 1783 patients in which 813 patients received deep and ACP groups.

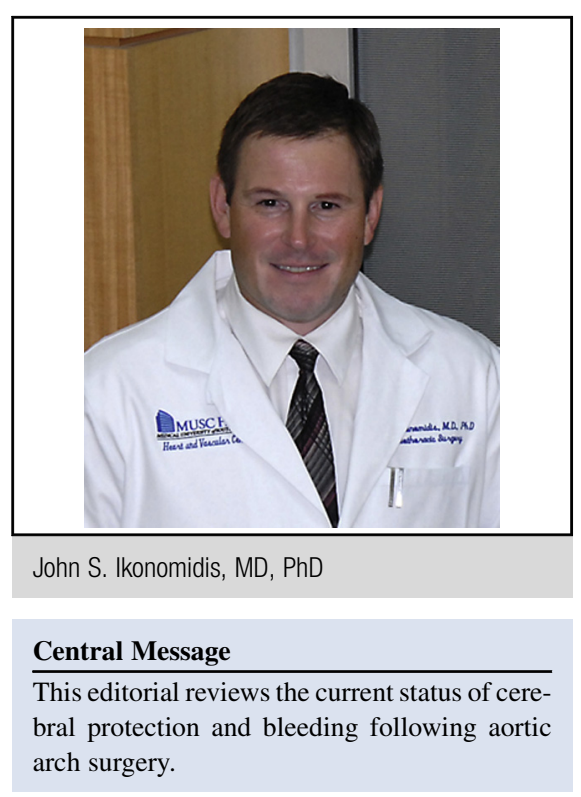

See Article page 376.

See Editorial Commentary page 383.

hypothermic circulatory arrest and 970 patients received moderate hypothermia and ACP. The results showed a significant reduction in stroke in the moderate hypothermia

Retrograde cerebral perfusion (RCP) was first introduced by Ueda and colleagues in $1990 .^{4}$ They reported that safe circulatory arrest periods could be extended up to $80 \mathrm{mi}-$ nutes with this adjunct. Numerous authors have reported success with this strategy, but concerns have been raised regarding the adequacy of brain perfusion with this technique, ${ }^{5}$ as well as increased incidence of transient neurologic dysfunction with longer circulatory arrest times. ${ }^{6}$ ACP, first described by Bachet and colleagues, ${ }^{7}$ Kasui and colleagues, ${ }^{8}$ and Matsuda and colleagues, ${ }^{9}$ maintains physiologic blood flow to the brain and can be delivered in a variety of ways. Analysis of the Japan Adult Cardiovascular Surgery database ${ }^{10}$ compared 2209 ACP with 583 RCP cases performed between 2005 and 2008 and found no differences in 30-day mortality and stroke, but a higher incidence of transient neurologic dysfunction in the RCP group. In contrast, a recent meta-analysis of 15 studies and a total of 5060 patients showed no differences in 30-day mortality, permanent neurologic dysfunction, 
or transient neurologic dysfunction. ${ }^{11}$ In addition, a meta-analysis of 32 studies comparing 3723 patients receiving bilateral ACP with 3065 patients receiving selective ACP showed similar results in terms of neurologic outcomes, but circulatory arrest times longer than 30 minutes were associated with increased mortality in the selective ACP group. ${ }^{12}$

The potential benefits of antegrade perfusion of the brain are intuitively obvious and, I believe, are borne out in the current data. In addition, limiting the lowest temperature for hypothermic circulatory arrest results in shorter cardiopulmonary bypass times and as such may limit bypassassociated coagulopathy postprocedure. This was shown in the meta-analysis performed by Tian and colleagues ${ }^{3}$; however, some centers have not been able to demonstrate improvements in hemostasis with higher hypothermic circulatory arrest temperatures. It is possible that these are experienced, high-volume centers that demonstrate good results regardless of the technique used. ${ }^{13}$

Of course, it is now possible to achieve total arch replacement without the use of bypass. A hybrid approach, which involves sequential great artery anastomosis to a branched graft attached to the ascending aorta followed by endovascular stent grating of the entire arch, can achieve the same result as an open operation without the issues related to cardiopulmonary bypass and circulatory arrest. In addition, purely endovascular approaches to the aortic arch are also being employed. The main concerns regarding these procedures include embolic stroke due to excessive manipulation of the arch with catheters, stent graft migration, and endoleaks. A preliminary meta-analysis comparing studies of hybrid versus open arch replacement showed a trend toward increased neurologic events in the hybrid debranching group, indicating that these techniques may not necessarily represent the definitive answer to limiting neurologic events. $^{14}$

\section{CONCLUSIONS}

Substantial experimental and clinical research has resulted in significant advancements in the way we approach the aortic arch surgically and have reduced neurologic and bleeding complications. Have we made progress? I believe that the answer is yes, but these 2 chinks in the armor continue to challenge us. As surgeons continue to push the envelope with refinements in cannulation techniques, cerebral protection strategies, and replacement devices, further improvements will continue to be made in this very challenging but rewarding field of cardiovascular surgery.

\section{References}

1. Griepp RB, Stinson EB, Hollingsworth JF, Beuhler D. Prosthetic replacement of the aortic arch. J Thorac Cardiovasc Surg. 1975;76:1051-63.

2. Gutsche JT, Feinman J, Silvay G, Patel PP, Ghadimi K, Landoni G, et al. Practice variations in the conduct of hypothermic circulatory arrest for adult aortic arch repair: focus on an emerging European paradigm. Heart Lung Vessel. 2014;6: 43-51.

3. Tian DH, Wan B, Bannon PG, Misfeld M, Lemaire SA, Kazui T, et al. A metaanalysis of deep hypothermic circulatory arrest versus moderate hypothermic circulatory arrest with selective antegrade cerebral perfusion. Ann Cardiothorac Surg. 2013;2:148-58.

4. Ueda Y, Miki S, Kusuhara K, Okita Y, Tahata T, Yamanaka K. Surgical treatment of aneurysms or dissection involving the ascending aorta and aortic arch utilizing circulatory arrest and retrograde cerebral perfusion. J Cardiovasc Surg (Torino). 1990;31:553-8.

5. Hagl C, Ergin MA, Galla JD, Lansman SL, McCullough JN, Spielvogel D, et al. Neurologic outcome after ascending aorta-aortic arch operations: effect of brain protection technique in high-risk patients. J Thorac Cardiovasc Surg. 2001;121: 1107-21.

6. Ehrlich MP, Hagl C, McCullough JN, Zhang N, Shiang H, Bodian C, et al. Retrograde cerebral perfusion provides negligible flow through brain capillaries in the pig. J Thorac Cardiovasc Surg. 2001;122:331-8.

7. Bachet J, Guilmet D, Goudot B, Dreyfus GD, Delentdecker P, Brodaty D, et al Antegrade cerebral perfusion with cold blood: a 13-year experience. Ann Thorac Surg. 1999;67:1874-8.

8. Kazui T, Inoue N, Yamada O, Komatsu S. Selective cerebral perfusion during operation for aneurysms of the aortic arch; a reassessment. Ann Thorac Surg. 1992;53:109-14.

9. Matsuda H, Nakano S, Shirakura R, Matsuwaka R, Ohkubo N, Ohtani M, et al. Surgery for aortic arch aneurysm with selective cerebral perfusion and hypothermic cardiopulmonary bypass. Circulation. 1989;80:I243-8.

10. Usui A, Miyata H, Ueda Y, Motomura N, Takamoto S. Risk-adjusted and casematched comparative study between antegrade and retrograde cerebral perfusion during aortic arch surgery: based on the Japan Adult Cardiovascular Surgery Database: the Japan Cardiovascular Surgery Database Organization. Gen Thorac Cardiovasc Surg. 2012;60:132-9.

11. Hu Z, Wang Z, Ren Z, Wu H, Zhang M, Zhang H, et al. Similar cerebral protective effectiveness of antegrade and retrograde cerebral perfusion combined with deep hypothermia circulatory arrest in aortic arch surgery: a meta-analysis and systematic review of 5060 patients. J Thorac Cardiovasc Surg. 2014;148:544-60.

12. Angeloni E, Melina G, Refice SK, Roscitano A, Capuano F, Comito C, et al. Unilateral versus bilateral antegrade cerebral protection during aortic surgery: an updated meta-analysis. Ann Thorac Surg. 2015;99:2024-31.

13. Hughes GC, Zhao Y, Rankin JS, Scarborough JE, O'Brien S, Bavaria JE, et al Effects of institutional volumes on operative outcomes for aortic root replacement in North America. J Thorac Cardiovasc Surg. 2013;145:166-70.

14. Bendetto U, Melina G, Angeloin E, Codispoti M, Sinatra R. Current status of open total arch replacement versus hybrid endovascular repair for aortic arch aneurysm: a meta-analysis of comparative studies. J Thorac Cardiovasc Surg. 2013;145:305-6. 